\title{
Preserving the owner's autonomy in networks of patient registries and biobanks
}

\author{
Martin Lablans*, Dennis Kadioglu, Marita Muscholl, Frank Ückert \\ From 7th European Conference on Rare Diseases and Orphan Products (ECRD 2014)
}

\section{Background}

To achieve statistical significance in rare disease research, bio- or data samples taken from one patient registry or biobank may need to be complemented by those of other institutions $[1,2]$. While a first overview of potential research partners can be obtained using public catalogues as established by BBMRI [3] or Orphanet [4], this article focuses on mediation services, which provide deeper insight on available material using criteria-based search on fine-grained, non-aggregated datasets. Until now, these datasets were provided either beforehand via regular uploads (central search, e.g. CRIP [5] and the NCI's specimen resource locator [6]) or on-demand via distributed queries (federated search, e.g. i2b2 SHRINE [7] and EHR4CR [8]). However, both ways give third parties whom the data or sample owners may neither know nor trust insight into their databases.

The requirement for self-disclosure places owners in a dilemma: On the one hand, they want to contribute to promising collaborative research projects. On the other hand, they "frequently hold proprietary views on their data" [9] and want to carefully consider with whom to share their assets collected over years without facing pressure of justification for rejecting a proposal.

\section{Results}

We propose a method to search distributed databases, yet fully keep their owner's data sovereignty: The decentral search exploits distributed, heterogeneous, highly sensitive datasets from equally heterogeneous systems for overarching research questions. Similar to other federated searches, the decentral search detects matching material in distributed data stocks. However, their query mechanism is replaced by a novel request mechanism that involves the owner with a high degree of control, who can (decentrally using their own registry or biobank systems) decide if and what to answer based on a specific project proposal. As no datasets ever leave their institution, they can reject projects without risking their good standing as a cooperative scientist. While the decentral search sacrifices real-time answers, it leads to several beneficial side effects: improved data protection due to data parsimony, tolerance for incomplete data schema mappings, flexibility with regard to patient consents and decreased effort when the network is initially joined.

\section{Conclusion}

The decentral search allows to exploit bio- or data samples while fully preserving their owners' data sovereignty. It is employed in the Consortium for Translational Cancer Research, one of the six German Centres for Health Research comprised of eleven university hospitals. The decentral search also marks the centrepiece of the OSSE national registry of rare diseases.

\section{Acknowledgements}

The German Consortium for Translational Cancer Research is funded by the German Federal Ministry of Education and Research. For more information, see http://www.unimedizin-mainz.de/dktk. OSSE is funded by the German Federal Ministry of Health as part of the "National Action Plan for Rare Diseases". For more information see http://osse-register.de.

Published: 11 November 2014

\section{References}

1. Asslaber M, Zatloukal K: Biobanks: transnational, European and global networks. Brief Funct Genomic Proteomic 2007, 6:193-201.

2. Aymé S: Report on rare disease research, its determinants in Europe and the way forward.Hivert V 2011.

3. Wichmann H-E, Kuhn KA, Waldenberger M, Schmelcher D, Schuffenhauer S, Meitinger T, Wurst SHR, Lamla G, Fortier I, Burton PR, Peltonen L, Perola M, Metspalu A, Riegman P, Landegren U, Taussig MJ, Litton J-E, Fransson MN, Eder J, Cambon-Thomsen A, Bovenberg J, Dagher G, van Ommen G-J, Griffith M, Yuille M, Zatloukal K: Comprehensive catalog of European biobanks. Nat Biotechnol 2011, 29:795-797.

4. Aymé S, Schmidtke J: Networking for rare diseases: a necessity for Europe. Bundesgesundheitsblatt-Gesundheitsforschung-Gesundheitsschutz 2007, 50:1477-1483.

\footnotetext{
* Correspondence: lablans@uni-mainz.de
}

University Medical Center, Mainz, Germany 
5. Schröder C, Heidtke KR, Zacherl N, Zatloukal K, Taupitz J: Safeguarding donors' personal rights and biobank autonomy in biobank networks: the CRIP privacy regime. Cell Tissue Bank 2011, 12:233-240.

6. Demchok J, Taube S, Fombonne B, Lubensky I: The National Cancer Institute (NCl) specimen resource locator. Eur J Cancer 2013,

49(Supplement 4):S37-S38, [Markers in Cancer: A Joint Meeting by ASCO, EORTC and $\mathrm{NCl}$ Abstract Book].

7. Weber GM, Murphy SN, McMurry AJ, MacFadden D, Nigrin DJ, Churchill S, Kohane IS: The Shared Health Research Information Network (SHRINE): a prototype federated query tool for clinical data repositories. J Am Med Inform Assoc 2009, 16:624-630.

8. Ouagne D, Hussain S, Sadou E, Jaulent M-C, Daniel C: The Electronic Healthcare Record for Clinical Research (EHR4CR) information model and terminology. Stud Health Technol Inf 2012, 180:534-8.

9. EURORDIS-NORD-CORD: Joint Declaration: 10 Key Principles of Rare Disease Patient Registries. 2012

doi:10.1186/1750-1172-9-S1-P3

Cite this article as: Lablans et al:: Preserving the owner's autonomy in networks of patient registries and biobanks. Orphanet Journal of Rare Diseases 2014 9(Suppl 1):P3.

\section{Submit your next manuscript to BioMed Central} and take full advantage of:

- Convenient online submission

- Thorough peer review

- No space constraints or color figure charges

- Immediate publication on acceptance

- Inclusion in PubMed, CAS, Scopus and Google Scholar

- Research which is freely available for redistribution

Submit your manuscript at www.biomedcentral.com/submit 